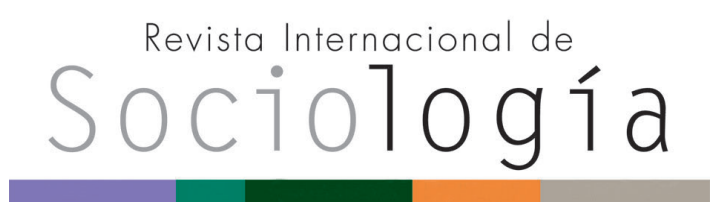

Revista Internacional de Sociología RIS vol. 73 (3), e021, septiembre-diciembre, 2015, ISSN-L:0034-9712

DOI: http://dx.doi.org/10.3989/ris.2015.73.3.e021

\section{DEL CAMPO FILOSÓFICO ESPAÑOL ENTRE EL FRANQUISMO Y LA TRANSICIÓN DEMOCRÁTICA. Una validación cuantitativa}

\author{
Francisco VázQuez García \\ Universidad de Cádiz, España. \\ francisco.vazquez@uca.es \\ Ildefonso Marqués Perales \\ Universidad de Sevilla, España. \\ imarques@us.es
}

Como citar este artículo / Citation: Vázquez García, F., Marqués Perales, I. 2015. «Sociología del campo filosófico español entre el Franquismo y la Transición democrática: una validación cuantitativa». Revista Internacional de Sociología, 73, 3. DOl: http://dx.doi.org/10.3989/ris.2015.73.3.e021

\begin{abstract}
Resumen
La más reciente investigación dedicada al análisis del campo filosófico español entre el tardofranquismo y la Transición, señaló la existencia de dos redes intelectuales: una, denominada «oficial», que aglutinaba a los filósofos de perfil más estrictamente académico (v. g. Sergio Rábade), y otra, designada como «alternativa», que integraba a los pensadores más vanguardistas (v. g. López Aranguren). Los materiales utilizados en La filosofía española. Herederos y pretendientes. Una lectura sociológica (1963-1990) (Vázquez García 2009), fueron objeto en esta obra de una aproximación cualitativa. Nuestro objetivo en este artículo, privilegiando la fiabilidad sobre la validez, es la realización de un análisis de correspondencias múltiples, en el que se han cuantificado más de 15 variables sobre cincuenta filósofos españoles. En las conclusiones se profundiza en las diferencias y similitudes entre los resultados obtenidos con las metodologías cualitativa y cuantitativa.
\end{abstract}

\section{Palabras Clave}

Análisis de correspondencias múltiples; Campo filosófico; Filosofía española; Sociología de la filosofía.

\section{SOCIOLOGY OF THE PHILOSOPHICAL SPANISH FIELD BETWEEN THE FRANCOIST REGIME AND THE TRANSITION TO DEMOCRACY. A quantitative validation}

Copyright: () 2015 CSIC. Este artículo de acceso abierto distribuido bajo los términos de la licencia Creative Commons Attribution-Non Commercial (by-cn) Spain 3.0. Recibido: 27/03/2014. Aceptado: 25/09/2014

Publicación online: 10/11/2015

\section{Abstract}

The latest research about the Spanish philosophical field between the late francoism and the democratic transition, pointed out the existence of two intellectual networks. On the one hand, an «official» section including the most scholar philosophers (e. g. Sergio Rábade). On the other hand, an "alternative» segment composed by the most vanguard thinkers (e.g. López Aranguren). La filosofía española. Herederos y pretendientes. Una lectura sociológica (19631990) (Vázquez García 2009) employed a qualitative approach. Our goal, using the same sources, is to employ a correspondent analysis in order to put emphasis on reliability over validity. More than 15 variables about 50 Spanish philosophers have been measured. The conclusions explores the differences and similarities between the results obtained with the qualitative and quantitative methodologies.

\section{KEYWORDS}

Multiple Correspondence Analysis; Philosophical Field; Sociology of Philosophy; Spanish Philosophy. 


\section{ESTADO DE LAS CUESTIÓN E INTENCIÓN DEL TRABAJO. UNA SOCIOLOGÍA DEL CAMPO FILOSÓFICO ESPAÑOL ENTRE EL TARDOFRANQUISMO Y LA TRANSICIÓN $^{1}$}

Los análisis del universo filosófico español entre la época del franquismo tardío y la consolidación de la democracia han proliferado en los últimos años, multiplicándose los enfoques y los marcos conceptuales utilizados ${ }^{2}$. Junto a revisiones de corte internalista, centradas en el estudio de las obras, ya sea yuxtaponiendo análisis de distintos autores y corrientes (Caballero Bono 2008; Savignano 2008; Garrido et al. 2009), o agrupándolos por áreas disciplinares (Metafísica, Filosofía de la Ciencia, Ética, etc.) (Jiménez y Maceiras 2002; Suances Marcos 2006), coexisten otros trabajos que, apuntando a los agentes más que a las obras, intentan aplicar el conocido «método de las generaciones». El principal achaque que se le puede objetar a estas monografías (Bolado 2001; Ruiz de Samaniego y Ramos 2002; Abellán 2005) es el recurso a un concepto insuficientemente elaborado de "generación», sin distinguir adecuadamente, como ya había hecho Mannheim (1993: 221-25), entre «situación», «complejo» y «unidad» generacionales (Gil Villegas 1996; 1997; Mauger 2009), lo que explica la contradicción en la que incurren recíprocamente estos estudios a la hora de establecer los cortes generacionales que estiman pertinentes (Vázquez García 2009: 19-24).

El trabajo de Bolado (2001) constituye un meritorio intento de recopilar prácticamente toda la producción filosófica española en el curso de la Transición. Sin embargo, su tendencia a imputar a la Transición política un excesivo poder causal en las transformaciones del campo filosófico -olvidando la autonomía de este- y el recurso a una discutible dialéctica entre «recuperación» y «recepción», merman considerablemente el valor explicativo y la inteligibilidad proporcionada por esta síntesis (Ribas 2006: 4243; Vázquez García 2009: 391-92).

Otras aproximaciones, dejando a un lado el puro análisis interno o el relato de las "generaciones» en su orden sucesivo, tratan de integrar los avatares del universo filosófico español en la época mencionada, dentro de un

1 Este trabajo se ha realizado gracias a la financiación de la Dirección General de Investigación del Ministerio de Ciencia e Innovación (España), dentro del proyecto «Vigilancia de fronteras, colaboración crítica y reconversión: un estudio comparado de la relación de la filosofía con las ciencias sociales en España y Francia (1940-1990)», referencia FFI2010-15196 (subprograma FISO).

2 No existe un acuerdo entre los historiadores a la hora de establecer unos límites cronológicos estrictos que marquen el inicio del Tardofranquismo y el final de la Transición (Fuentes Aragonés: 2006). En el estudio que nos ocupa, la cronología remite a acontecimientos específicamente filosóficos, abarcando un proceso situado aproximadamente entre la primera edición de las Convivencias de Filósofos Jóvenes (1963) y la fundación de la revista Isegoría (1990), que sella el control del Instituto de Filosofía del CSIC por los discípulos de Aranguren. campo intelectual más vasto. Así sucede por ejemplo con la panorámica ofrecida por Gracia y Ródenas (2009: 114159), donde se cartografía el papel desempeñado por los distintos grupos y autores dentro del «boom» conocido por el género ensayístico entre los últimos años del franquismo y el periplo inicial de la Transición.

A estas contribuciones hay que sumar los trabajos que presentan el escenario filosófico español -en su totalidad o solo en parte- de la época, interpretándolo a partir de una clave hermenéutica determinada. Este es el caso de los estudios recientes de Eugenia Afinoguénova (2003) y Gabriel Plata (2010). El primero, realizado desde el ámbito de los Cultural Studies, da cuenta de la recepción española de las corrientes estructuralistas, neonietzscheanas y postestructuralistas, poniéndola en conexión con la emergencia de una subjetividad débil o «idiota», ligada a la expansión del individualismo consumista en nuestro país.

No alejada de esta hipótesis, pero incluyendo una valoración abiertamente negativa de esa pendiente hacia el sujeto narcisista de la sociedad de consumo, se sitúa la obra de Gabriel Plata (2010). Elaborada desde la perspectiva de la historia de las ideas y de los intelectuales, este trabajo expone las contribuciones de los principales pensadores del momento (Aranguren, Tierno Galván, Gustavo Bueno, Sacristán, García Calvo, Sánchez Ferlosio, Eugenio Trías y Fernando Savater) a partir del doble proceso constituido por el descrédito del marxismo y la deriva, tras la desilusión del postmayo sesentayochista, hacia el neoliberalismo, la postmodernidad y el auge del individualismo ético en la sociedad de consumo.

Pese a alguna tentativa pionera ${ }^{3}$, por tanto, el examen sociológico del campo de la filosofía española en el periodo que va desde el inicio del Concilio Vaticano II hasta la fundación en 1990 de la revista Isegoría ${ }^{4}$, estaba por realizar. Este análisis es el que se ha emprendido en la obra reciente de Francisco Vázquez, La filosofía española. Herederos y pretendientes. Una lectura sociológica (1963-1990), publicada en 2010. En esta investigación se exploraban las transformaciones del universo filosófico español en el mencionado periodo a partir de los instrumentos metodológicos proporcionados por una disciplina en estado naciente: la sociología de la filosofía. Esta pretende, ante todo, evitar la falsa

3 El trabajo de Cirilo Flórez (1978: 130-131) trata de reconstruir las redes filosóficas españolas de la época apoyándose en la sociología de los "colegios invisibles" desarrollada por D. J. Price. La objeción principal a este trabajo es que la identidad de cada grupo es delimitada a partir de imágenes creadas y propagadas por la prensa. Por otro lado, desde el ángulo de la historia social de la filosofía, es digno de mención el trabajo de Serra (2010), aunque limitado al ámbito de la Lógica en Cataluña

4 Estas fechas indican por una parte el comienzo de la apertura del campo religioso español a la penetración de corrientes del pensamiento moderno y por otra, la consolidación de la modernidad filosófica en el Instituto Luis Vives (CSIC), una vez que Javier Muguerza, tras décadas de predominio opusdeísta, asumiera su dirección en 1986 
dicotomía establecida entre las perspectivas internalista y externalista, atendiendo a la experiencia filosófica en todas sus facetas, esto es, no solo a la dimensión intelectual o cognitiva, sino también a otros aspectos que entrelazan lo institucional con lo afectivo, lo expresivo y el poder: las redes de intereses profesionales y los procesos de acumulación de capital académico; las tomas de posición política y religiosa en relación con el origen familiar, la trayectoria escolar y la procedencia de clase de los filósofos ${ }^{5}$.

En Vázquez García (2009) se trataba de combinar las herramientas conceptuales que en esta disciplina habían suministrado los tres principales enfoques existentes: la sociología de los campos filosóficos elaborada por Bourdieu y sus discípulos (Pinto, Boschetti, Fabiani), la sociología de los rituales y redes de filósofos (Randall Collins) y la sociología del conocimiento filosófico (Martin Kusch). Se pretendía articular a los tres tipos de metodología en una síntesis histórica que ha sido objeto de cierta discusión dentro de la comunidad filosófica española 6 , y que se encuadra en un trabajo colectivo que viene prolongándose desde hace varios años ${ }^{7}$.

En el presente trabajo se trata de aportar elementos probatorios a las hipótesis planteadas por Vázquez (2009), pero recurriendo ahora, no solo al análisis sociológico cualitativo, sino a la utilización de técnicas cuantitativas, particularmente al análisis de correspondencias múltiples. Ciertamente, el uso de métodos cuantitativos en la historiografía filosófica sigue siendo excepcional. En sociología de la filosofía, la cuantificación de los datos solo se ha realizado de modo muy parcial, como puede advertirse

5 Sobre esta metodología, véanse los trabajos de Moreno Pestaña (2005; 2007 y 2012a).

6 Entre los días 1 y 2 de junio de 2010, organizadas por la Fundación Ortega y Gasset, la Facultad de Filosofía de la UNED y la financiación del Ministerio de Ciencia e Innovación, se celebraron en Madrid unas Jornadas tituladas "La Transición Filosófica Española. Debate a propósito del libro de Francisco Vázquez, La filosofía española. Herederos y Pretendientes" En las Jornadas participaron, además del autor del libro, Javier Muguerza, Victoria Camps, Miguel Ángel Quintanilla, Félix Duque, Jacobo Muñoz, José Luis Villacañas, Juan Manuel Navarro Cordón, Antonio Campillo, Antonio García Santesmases, entre muchos otros. Sobre el libro se han publicado un total de 15 comentarios y reseñas; citamos solo las más relevantes: Barrios (2010), Gracia (2010), Villacañas (2010), Muguerza (2010), Sauquillo (2011), Campillo (2011), Ribas (2011) y Moreno Pestaña (2012c).

7 Este trabajo tiene su núcleo en el grupo de investigación HUM-536 de la Universidad de Cádiz, que ha desarrollado dos proyectos de investigación sobre esta temática financiados por el Ministerio español de Ciencia e Innovación: HUM 200604051/FISO (2006-2009) y FFI2010-15196, subprograma FISO (2010-2013). Entre los trabajos derivados de estos proyectos pueden citarse Moreno Pestaña y Vázquez García (2006), Moreno Pestaña (2006; 2008 y 2012b), Marqués Perales (2008), Galván García (2010), Vázquez García (2010), Estrella González (2012), además del monográfico sobre "Sociología de la filosofía en España», editado por Daimon. Revista de Filosofía en 2011 y coordinado por Francisco Vázquez. en algunas indicaciones de Collins (2005: 44-45; 68-70) a la hora de jerarquizar a los filósofos de las redes, 0 de Kusch (1995: 95, 123-127) al ponderar bibliométricamente la importancia del debate del psicologismo en la filosofía alemana (1901-1920) o la evolución del poder académico con respecto a los psicólogos y filósofos alemanes en ese periodo. Se trata de un recurso más o menos tangencial al análisis estadístico. Distinto es el caso de Pinto (2007: 184-199), donde encontramos, siguiendo el modelo sugerido por Pierre Bourdieu (1984: 106-167) en su sociología del campo académico, la utilización del análisis de correspondencias para reconstruir las estructuras y dimensiones del campo filosófico francés entre 1960 y 2000.

En España no se ha realizado hasta la fecha nada parecido. Se puede mencionar un temprano trabajo, dirigido por Miguel Ángel Quintanilla (1973), quien junto a un grupo de estudiosos de la Universidad de Salamanca, se apoyó en una muestra de seis revistas españolas de filosofía, analizadas entre 1960 y 1971, con objeto de cuantificar el número (30.000) y los tipos de citas (correspondientes a más de 3000 autores) recogidas en un total de 512 artículos publicados. Se trataba así de reconstruir la evolución comparada de las materias y del canon de pensadores en la filosofía española de ese periodo. Se estaba por tanto ante un análisis que apuntaba a evaluar los textos y los autores más citados, así como las temáticas más frecuentadas. Es decir, un examen que concernía a la bibliometría de los bienes filosóficos en circulación más que a la sociología de los propios filósofos; al estudio de la producción más que de los productores.

\section{Algunas hipótesis}

En su trabajo, Francisco Vázquez puso a prueba una serie de hipótesis sobre la estructura y las transformaciones del campo filosófico español comprendido entre 1963 y 1990. Algunas de estas hipótesis forman parte del cuerpo teórico de la sociología de la filosofía. Por ejemplo, el supuesto de que la actividad filosófica tiene un carácter colectivo (frente al mito del pensador solitario), se estructura como un campo social y se realiza a través de redes y nódulos de sociabilidad intelectual.

En el mismo orden general se sitúa la hipótesis según la cual los cambios del campo filosófico deben explicarse poniendo en relación las transformaciones internas de sus estructuras con las alteraciones producidas en otros universos sociales: demografía escolar, campo editorial, campo político y religioso y espacio de las posiciones de clase y fracciones de clase.

De un modo más específico, el trabajo de Francisco Vázquez distingue, en la época mencionada, dos grandes redes de pensadores que obedecen a formas diferenciadas de socialización filosófica: la llamada «red oficial» (los «herederos»), que se identifica con el tipo de filosofía 
predominante, tras la guerra civil, en las instituciones de investigación y educación superior, y la denominada «red alternativa», que se vincula a una filosofía subordinada en el ámbito académico pero que acabó convirtiéndose en hegemónica en el plano de la consagración intelectual. La «transición filosófica», esto es, la homologación de la filosofía que se practicaba en España con las corrientes que conocían su pleno desarrollo en el mundo occidental del último tercio del siglo XX, habría sido el resultado de un encuentro entre la propia deriva interna de la red oficial, en la que algunos sectores iniciaron una apertura a la modernidad filosófica, y la gestación de nuevos nódulos de pensadores en el interior de la red alternativa.

Cada una de las redes mencionadas se corresponde con un estilo de socialización filosófica y por tanto con un habitus filosófico diferenciado. Las secciones de filosofía de la Universidad Central de Madrid y de Barcelona, el Instituto Luis Vives del CSIC y los centros de educación superior bajo tutela eclesiástica, que dominaban, todavía en las décadas de 1960 y 1970, la vertiente temporal (académica) de la institución filosófica, promovían un tipo de carrera y de perfil de filósofo que se ajustaba bien al modelo del insider ${ }^{8}$.

Con un origen social relativamente modesto y a menudo de procedencia rural, estos «oblatos» del mundo académico solían ser alumnos aplicados y con expediente académico ejemplar. Para la confección de sus tesinas y tesis doctorales, optaban por temas y autores de un canon ortodoxo que, a partir de la década de los sesenta, se amplió incorporando a los clásicos modernos y contemporáneos (Kant, idealismo alemán, Husserl, Heidegger). Por otro lado era frecuente en estos insiders la estancia de estudios en Alemania, en particular gracias a una beca del Instituto Luis Vives, y el paso por un centro de bachillerato tras ganar las correspondientes oposiciones a cátedra. En general, estos insiders accedían pronto al funcionariado universitario, ocupaban cargos en la institución y solían caracterizarse por una producción de corte erudito o destinada al mercado escolar (manuales de filosofía para el bachillerato y la universidad, antologías de textos, etc.). Frecuentaban raramente los medios de comunicación y las revistas intelectuales y publicaban en revistas profesionales y especializadas y en colecciones editoriales de proyección académica (como la «Biblioteca Hispánica de Filosofía» en Gredos). Su respaldo simbólico lo constituía principalmente el conocimiento técnico de la historia de la filosofía, acompañado a veces de una familiaridad importante con los estudios teológicos.

El otro polo englobaba un tipo de docencia filosófica realizada fuera de las secciones de filosofía (y cuando tenía lugar en estas, impartida en disciplinas jerárquicamente subordinadas, como Ética y Sociología, Estética o Psicología) e incluso al margen del espacio universitario. Esta práctica de

8 Se retoma aquí, modificándola, la distinción ideal típica entre filósofo insider y outsider utilizada por Gil Villegas (1996: 102-108). la filosofía se concentraba en una red intelectual con fuerte presencia de orteguianos católicos y de falangistas en vías de evolución ideológica hacia la izquierda, en un universo institucional que iba desde el Instituto de Humanidades y el Instituto de Estudios Políticos hasta la Sociedad de Estudios y Publicaciones, pasando por las asignaturas filosóficas presentes en las facultades de Derecho, Ciencias Políticas y Económicas, Filosofía y Letras (materias comunes) o la escuela de Arquitectura.

Aquí aparecían profesores con un formato diferente, de outsider: una procedencia social generalmente más elevada y de raíces urbanas; cierta preparación en ciencias sociales o en lógica y metodología de la ciencia, o bien contando con un importante capital artístico y literario; una trayectoria académica más irregular, mayor proximidad a los medios de comunicación y a las revistas intelectuales y una mayor proclividad hacia el ensayo e incluso hacia la creación literaria.

El modelo del insider se localiza en los nódulos filosóficos de la red oficial, incluidos aquellos que iniciaron un movimiento de renovación en la década de los sesenta. En efecto, esta red perdió pronto su hegemonía intelectual, a pesar de iniciarse en ella un proceso de renovación que da lugar a dos nódulos representantes de la ortodoxia académica. Por una parte, el núcleo opusdeísta, que a la altura de 1965 contaba con catedráticos en casi todas las secciones españolas de filosofía, aunque su centro visible lo constituía la Facultad de Filosofía de la Universidad de Navarra (fundada en 1962) y su órgano principal el Anuario Filosófico editado desde 1968 por este organismo. A este enclave pertenecían filósofos como Leonardo Polo, Millán Puelles o Jesús Arellano. Su proyecto puede ser entendido como una tentativa para realizar una filosofía rigurosa y desideologizada, ensamblando la pureza formal de las categorías escolásticas con injertos procedentes, en su mayor parte, de la fenomenología de Husserl. Se trataba de «asimilar» los aspectos más formales de la modernidad filosófica preservando un fondo de contenidos tradicionales. En cierto modo practicaban una suerte de "taxidermia» intelectual: disecar el legado tomista utilizando una piel fenomenológica.

Por otra parte, a comienzos de los años sesenta, autores como Sergio Rábade, procedentes también de la red oficial, van a proponer una renovación del canon textual. Hasta entonces este había estado compuesto casi en exclusiva por el tronco que iba desde Platón hasta Santo Tomás pasando por Aristóteles y secundariamente por San Agustín, de modo que la exposición de la filosofía moderna era un decadente catálogo de errores que solo cabía refutar. Autores como Rábade en la Universidad de Madrid, y posteriormente Fernando Montero Moliner, en la Universidad de Valencia, defendieron una redefinición del canon textual, incorporando la filosofía moderna desde Descartes hasta Heidegger, pasando por los empiristas, Kant, Hegel y Husserl. 
Junto al academicismo ortodoxo del Opus y de los rabadesianos, comienza a configurarse a finales de los años sesenta un academicismo heterodoxo que hace valer una filosofía de factura netamente universitaria y con un alto grado de tecnicismo, pero cuyas referencias teóricas ya no están conformadas ni por una escolástica disecada de la fenomenología ni por una glosa hermenéutica del canon renovado. Lo que se afirma es, por un lado, un «materialismo académico» nucleado en la Universidad de Oviedo en torno a Gustavo Bueno y un «análisis filosófico» practicado en Valencia por Manuel Garrido y sus discípulos. Los órganos respectivos de estos dos nuevos grupos filosóficos serán la revista Basilisco (1978) y la revista Teorema (1971).

Mientras tanto, la red alternativa, en la que predominaba el perfil del outsider, comenzó a dar frutos. En primer lugar, tomando a López Aranguren como líder carismático y a Javier Muguerza como líder organizativo, se fue conformando en la segunda mitad de los años sesenta un nódulo sumamente activo y extendido, donde podían diferenciarse tres polos. Se reconoce en primer lugar un polo donde prevalece el capital religioso, de modo que el proyecto de «ensanchar» la razón, que singulariza en general al núcleo de Aranguren -una racionalidad distante a la vez del dogmatismo escolástico y del cientificismo positivista- se concreta en una propuesta de carácter escatológico. Los autores que la formulan -contando en general con disposiciones religiosas muy arraigadas-combinan las aportaciones de las «teologías radicales» y de un marxismo leído a partir de Kant o de Hegel -especialmente filtrado a través del legado utópico de Ernst Bloch y de la Escuela de Frankfurtpara producir un discurso donde cristaliza la "esperanza» en la reconciliación de los contrarios que desgarran a la razón y mantienen al hombre en una postración alienada. En este polo escatológico convergen las trayectorias de filósofos vinculados al Instituto Fe y Secularidad (Rodríguez de Lecea 1990), o a la recuperación actualizada de Hegel y de Kant en clave emancipatoria, 0 al redescubrimiento del pensamiento hispánico y hebreo. Los nombres de Álvarez Bolado, Gómez Caffarena, Ramón Valls, Pedro Cerezo, Adela Cortina, José Luis Abellán, Cirilo Flórez 0 Reyes Mate, se reconocen en este sector.

En un área intermedia, el capital religioso cede su prioridad al capital científico. Este puede identificarse con la competencia en la lógica simbólica y el análisis lingüístico, pero también con un saber vinculado a las ciencias sociales y jurídicas. La apertura al conocimiento científico como fuente crucial de la experiencia filosófica se encuentra ya afirmada en un autor como Zubiri, situado en las raíces dinásticas de este grupo. La calificación de "científico» no debe llevar a la identificación de este sector filosófico con una mesnada defensora del positivismo o del cientificismo. Se trata en cambio de rechazar, al mismo tiempo, el dogmatismo metafísico y el cientificismo autosatisfecho, haciendo valer la función crítica de una racionalidad científica capaz de autoilustración. Aquí comparece, por ejemplo, el proyecto de Javier Muguerza en La Razón sin Esperanza: una razón analítica utilizada para desenmascarar el añejo dogmatismo escolástico y para evitar autocríticamente que el propio análisis filosófico se convierta en la filosofía oficial de un franquismo tecnocrático. Aquí se emplaza también la utilización de la historia y la sociología del derecho por parte de Elías Díaz, buscando franquear la alternativa entre el iusnaturalismo y el positivismo jurídico. A estos nombres habría que añadir los de Alfredo Deaño y José Hierro Pescador, autores vinculados al mismo tiempo a Revista de Occidente y al legado orteguiano y forjados en la tradición de la filosofía analítica. Revistas como Sistema -fundada en 1973 por un grupo de intelectuales afines al socialismo y dirigida por Elías Díaz- y Teorema -órgano del nódulo de Garrido muy frecuentado por los analíticos de la Autónoma de Madrid- sirvieron para expresar las perspectivas filosóficas de este sector. Por otro lado esta región científica constituirá asimismo el punto de llegada de otros pensadores venidos de otras regiones, como Miguel Ángel Quintanilla, procedente del grupo de Salamanca (Cruz Hernández) y de los aledaños del nódulo de Bueno, y pronto convertido en primer animador (gracias al diccionario que coordinó) de la red alternativa; lo mismo cabe decir de su discípulo Vargas-Machuca, de Celia Amorós -procedente del nódulo valenciano regido por Garrido- y de Manuel Cruz -más joven, vinculado simultáneamente a Emilio Lledó y al círculo de Sacristán. Los casos ya mencionados de Peces-Barba, Rubio Carracedo, Javier Sádaba y Victoria Camps, ejemplifican la incorporación de algunos cristianos procedentes del polo escatológico en el sector agnóstico y más escéptico asociado al polo científico. Aquí también terminará desembocando la trayectoria de Javier Echeverría, un autor inicialmente incluido, como se verá, en otra región del continente arangureniano.

El tercer sector del nódulo de Aranguren estaría formado por un polo artístico, donde tendería a prevalecer la posesión de un capital vinculado al conocimiento de la literatura y a la familiaridad con las artes plásticas. García Calvo en Madrid y José María Valverde en Barcelona, serían los mentores respectivos de esta región filosófica. Aquí se advierte también la pretensión de ampliar el marco de una racionalidad confinada en los estrechos límites de la ciencia y la tecnología, rechazando al mismo tiempo todo intento de subordinar el ejercicio de la razón a la dogmática religiosa o al marxismo doctrinario. Por este motivo en algún momento -particularmente en los primeros años setenta- este polo se presentó como una cuarta vía, alejada al mismo tiempo de la escolástica, del cientificismo analítico y del escatologismo marxista. Se entiende que la actividad de la razón pasa por el encuentro y la acogida de lo irracional. En este sentido, frente a las narrativas reconciliadoras, se admiten los límites y la futilidad de la existencia, pero al mismo tiempo, frente a las estrechas miras del 
cientificismo y la filosofía analítica, se alberga la voluntad de traspasarlos. En la medida en que la religión y la ciencia se empeñaban en domesticar esta alteridad sometiendo su resistencia a un fundamento estable y luminoso, ambas quedaban descartadas como experiencias filosóficas cruciales. Esta se encontraba en el arte, que da cabida a lo que escapa a la razón -la locura, la embriaguez, la pérdida de la individualidad, lo místico, lo siniestro, lo mágico- sin abolir su diferencia radical. El artista es la figura que encarna a una razón ambivalente, pues capta lo pleno pero en formas huidizas.

Junto a este vasto «nódulo de Aranguren», que llegará a ser dominante en los años ochenta, hay que referirse a otro nacido también de la red orteguiana. Se trata del «nódulo Sacristán», constituido en torno al filósofo barcelonés, y que combinaba una epistemología de referencias analíticas y unos planteamientos ético-políticos vinculados al marxismo. Su punto de partida fue el Col.lectiu Crítica de Barcelona, constituido a mediados de los años setenta. Las revistas que vertebrarán este grupo verán la luz a finales de esa década. Se trata de Materiales y de Mientras Tanto. Los autores situados en la órbita de Sacristán suelen tener una fuerte relación con las ciencias sociales y una sólida formación epistemológica, además de implicarse activamente en el campo político. Aquí destacan filósofos como Jacobo Muñoz, Francisco Fernández Buey, Toni Doménech, Ramón Capella, Manuel Cruz, Félix Ovejero y José María Ripalda9?.

En este trabajo se intenta, en cierto modo, poner a prueba estas hipótesis sobre las redes y nódulos mediante instrumentos de prueba de carácter cuantitativo.

El análisis biográfico y bibliográfico realizado sobre la muestra de estos cincuenta filósofos españoles nos ha permitido recoger en distintos protocolos de observación una información muy rica y variada que hemos codificado con la intención de poder cuantificarla. Hemos recogido información relativa tanto al campo filosófico como extrafilosófico.

\section{VARIABLES}

\section{Variables internas al campo filosófico}

Tres son los conjuntos de variables que hemos establecido a la hora de estudiar el campo filosófico: aquellas que tienen que ver con el trabajo científico-intelectual, aquellas otras que tratan de dar cuenta de la labor realizada en el campo administrativo universitario y, en último lugar, las relativas al sector editorial.

9 El grupo de filósofos de izquierdas vinculado a la editorial Ciencia Nueva y que más tarde editaría la revista Zona Abierta, puede considerarse como el equivalente madrileño de lo que representaba, en Barcelona, el nódulo de Sacristán. Valeriano Bozal y Ludolfo Paramio serían quizás los pensadores más destacados de este grupo (Vázquez García 2009: 374-375).
Dentro del conjunto de variables científico-intelectuales se hallan los tipos de capital cultural, el número de citas contenidas en el Information Society Index Web of Knowledge (ISI), el número de tesis doctorales dirigidas, el país extranjero preferente de acogida en el que se formaron nuestros filósofos, el tipo de premios obtenidos y el año de acceso en el que se obtuvo la cátedra. Los tipos de capital cultural eficientes en el campo son los siguientes: historia de la filosofía, ciencias formales y empíricas, arte y literatura y teología. Los países extranjeros han sido agrupados en distintas áreas, como la germana (Alemania y Austria), francófona (Francia y Bélgica), anglosajona (Reino Unido, Estados Unidos y Canadá) y mediterránea (Italia). Los premios obtenidos han sido divididos en tres tipos: académico, vanguardista y mixto. El primero privilegia la adaptación a los cánones universitarios; el segundo promueve la ruptura con la ortodoxia y el tercero se sitúa en una región fronteriza, esto es, atiende a la innovación pero sin potenciar la radicalidad iconoclasta característica del segundo tipo. Un ejemplo del primero lo representaría los premios extraordinarios de tesis doctoral; una variante del segundo la encontramos en el Premio Anagrama de Ensayo y una ilustración del tercero la ofrece el Premio Nacional de Ensayo, brindado por el Ministerio de Cultura. Aquellos en los que no consta la recepción de premio alguno, quedan incluidos en la categoría de no premiados.

En lo que concierne a las variables pertenecientes al campo administrativo hay que a hacer referencia a los cargos ocupados. Estos son de tipo universitario, intelectual político y acumulativo. El primero abarca el desempeño de responsabilidades de gestión en la vida universitaria ( $v$. g. rector); el segundo es el que tiene una condición más abierta y se refiere a cargos de responsabilidad en la vida intelectual (v. g. presidente de un ateneo o director de una colección editorial); el tercero implica el ejercicio de responsabilidades políticas a escala estatal, autonómica 0 local (v. g. diputado en las cortes o consejero autonómico). Finalmente, el tipo acumulativo alude a la suma de cargos correspondientes a dos o más de los tipos anteriores.

Las variables relativas al campo editorial son tres: la existencia de libros traducidos a otras lenguas en la obra del autor considerado, el tipo de editorial de preferencia y el género de producción. Las editoriales pueden ser, al igual que los premios, de perfil académico, y, además, de orientación pedagógica, ensayística y de más de una clase. Y el tipo de producción se distingue por géneros: escolar-erudito, ensayístico y de producción mixta.

\section{Variables externas al campo filosófico}

La diversidad de materiales analizados nos ha permitido recoger variables relativas al origen social de los sujetos. Hemos conseguido ubicar a los filósofos en su posición social de partida, de origen, codificando la clase social de 
sus padres. Combinando relaciones de propiedad, de conocimiento y de mando obtenemos las siguientes clases sociales: grandes propietarios, profesiones liberales, pequeños funcionarios (maestros, administrativos), pequeños propietarios y obreros. Esta división está basada en la clasificación HISCO que es un sistema clasificatorio construido para ser aplicado a ocupaciones a un nivel histórico (Leeuwen, Maas, y Miles 2002).

Asimismo, hemos logrado información acerca del tipo de colegio en el que los filósofos de la muestra estudiaron. Estos son colegios privados, privados pero de adscripción religiosa y públicos laicos. Este tipo de dato no solo nos vale para enriquecer el perfil relativo al origen social de los filósofos, sino que creemos que puede tener una repercusión en sus elecciones teórico-filosóficas futuras.

Dada la importancia que tenía la influencia de la procedencia geográfica sobre la estructura de oportunidades de los individuos, también hemos seleccionado información relativa al hábitat de origen de los sujetos. De esta forma, distinguimos entre grandes capitales, capitales de provincia y pueblos.

Finalizamos esta sección dando cuenta de la actividad de los filósofos analizados en el campo mediático y la militancia política. El estudio de estos campos es especialmente interesante, ya que ambos pertenecen a lo que se ha venido denominando campo de poder (Bourdieu 1996; 2000). Recogiendo información respecto al primero, tratamos de considerar la participación de los filósofos en los medios de comunicación masiva. Como es sabido, estos tienen el poder de publicitar y dar una mayor visibilidad a las ideas esgrimidas por los filósofos, dándoles un mayor acceso a lo que ha venido denominándose el «público culto». Más que en ningún otro ámbito epistemológico, el éxito del «ensayo filosófico» depende en gran medida de las críticas de libros, de las columnas periodísticas o de la participación en debates radiofónicos y televisivos. En este sentido, son especialmente interesantes, como no podría ser de otra forma, los años sin «mordaza» de la transición política española (Barrera 1995). Vamos a emplear una variable ordinal compuesta de cuatro categorías: alta participación en los medios de comunicación, media, baja o ninguna. En lo que respecta a la militancia política, hacemos constar si los filósofos ocupan cargos de responsabilidad en alguna organización política o sindical, y si su militancia es permanente, coyuntural o inexistente.

Por último, se selecciona información acerca de la pertenencia a organizaciones religiosas de cada una de las unidades que componen la muestra. La primera categoría implica el sacerdocio o la pertenencia temporal o permanente a una orden religiosa; la segunda se refiere al paso formativo por un seminario diocesano; la tercera («relación de cercanía») comprende aquellos sujetos en cuya trayectoria se constata un componente religioso relevante pero coyuntural. Por último, se señala la ausencia de indicadores de pertenencia a organizaciones religiosas. Estos responden a la importancia reconocida a este tipo de experiencia en la formación de las vocaciones filosóficas en el contexto español de la época considerada. En el anexo, exponemos las medidas estadísticas principales obtenidas tanto para las variables internas al campo filosófico como las externas.

\section{Método}

A la hora de dar cuenta de las asociaciones que podrían establecerse entre los datos recogidos, hemos optado por el análisis de correspondencias múltiples. Puesto que nuestra finalidad consiste en comprobar si la información recogida -que creemos que puede organizar el campo filosófico español-, puede reflejar la existencia de una red oficial y otra alternativa, hemos de partir de un análisis de naturaleza inductiva. Claramente, en este caso, lo que nos interesa saber es si los datos siguen a nuestro modelo y no al revés (Le Roux y Rouanet 2004). O dicho de otra forma, queremos comprobar cuál es la estructura de los datos $y$, después, ver si nuestro modelo se ajusta a ellos. No estamos interesados en una técnica de independencia o, dicho de otra forma, en la predicción de una variable a partir de la combinación lineal de variables independientes. Más bien, lo que pretendemos es comprobar cómo se vincula entre sí un conjunto múltiple de variables. Bourdieu objetaba que en los análisis de independencia «las relaciones singulares entre la variable independiente (como puede ser la opinión pública) y unas variables dependientes como el sexo, la edad, la religión o, incluso el nivel de instrucción, los ingresos y la profesión, tienden a disimular el conjunto de relaciones que constituyen el verdadero principio de la fuerza y de la forma específica de los efectos registrados en tal correlación particular» (1982: 188).

El análisis de correspondencias múltiples es una técnica multivariante de la familia de los análisis factoriales especialmente adaptada para reducir la complejidad de las tablas formadas con datos categóricos. Esta técnica tiene varias virtudes. En primer lugar, nos permite realizar una «representación gráfica elegante y simple que permite una rápida interpretación y comprensión de los datos» (Greenacre 2008: 9). Esta es una técnica que ha sido abundantemente empleada en ciencias sociales puesto que resume la información contenida en tablas de contingencia en un diagrama de dispersión. Este visualiza puntos que representan datos en relación a un eje de coordenadas horizontal $(\mathrm{x}$ ) y vertical $(\mathrm{y})$. Toma los $n$ casos como la filas de una tabla en la que cada columna $v_{\text {! }}$ es una variable analizada.

El análisis de correspondencias múltiples se basa en el estadístico ji-cuadrado 0 , más exactamente, en su distancia, que es una distancia euclídea ponderada. Su utilización nos permite representar la distancia entre perfiles modificando los perfiles antes de su representación gráfica. 
El análisis de correspondencias múltiples goza de una gran simplicidad a la hora de su interpretación. Dos individuos gozan de afinidades en el espacio si comparten propiedades (en la terminología propia del análisis de correspondencia se emplea el término modalidad) y, por ello, estarán cercanos en el espacio construido. En nuestro caso de estudio, dos filósofos se hallarán cercanos en el espacio de correspondencia si han obtenido la misma puntuación en las variables recogidas.

Asimismo, dos modalidades se hallarán cercanas si han sido escogidas por los mismos individuos. En nuestro caso, por poner un solo apunte, si las modalidades arte y literatura (como elemento dominante del capital cultural) se hallan cercanas a Francia (como formación extranjera) y a galardones mundanos (premios) es porque existe una serie de filósofos que las han elegido. Puesto que se guarda la misma distancia en todas las direcciones, dos individuos o propiedades que guardan la misma distancia respecto a otros dos individuos o propiedades pero en un sentido contrario guardan el mismo grado de afinidad o diferencia.

\section{Resultados}

En el Gráfico I, puede apreciarse el diagrama de correspondencias múltiples que representa el campo filosófico español según las variables seleccionadas. El paquete estadístico empleado ha sido el SPSS y el método de normalización usado para este programa, tal como recomienda Greenacre (2008), ha sido el de normalización por variable. Las modalidades internas al campo provenían de las variables científico-intelectuales ('edad de acceso a la cátedra', 'capital cultural', 'citas ISI', 'países extranjeros de formación', 'tesis dirigidas' y 'premios otorgados'), administrativas ('cargos ocupados') y editoriales ('libros traducidos', 'editorial de preferencia' y 'tipo de producción'). El alfa de Crombach adquiere una media de 0,9 para las dos dimensiones, un guarismo excelente.

Las correlaciones entre variables han sido altas llegando en algunos casos a una correlación del 0,7 (v. g. 'experiencia política' y 'presencia mediática con cargos'; 'presencia mediática' y 'tipo de producción'), un 0,6 (v. g. 'tipo de producción' y 'elemento dominante del capital cultural'; 'tipo de producción' y 'cargos'; 'tipo de producción' y 'presencia mediática') y del 0,50 (v. g. 'elemento dominante' y 'premios'; 'libros traducidos' y 'número de citas'; 'cargos' y 'editorial de preferencia'; 'libros traducidos' y 'premios', 'tipo de producción' y 'editorial de preferencia').

La inercia obtenida ha sido de un $62,8 \%$ con un $65,5 \%$ obtenido en la primera dimensión y un $60 \%$ en la segunda. La dimensión primera divide el campo en dos perfiles claramente diferenciados. A medida que nos desplazamos de arriba abajo transitamos de las propiedades que indican un ethos proclive a la transformación del mundo a otro más inclinado a las actitudes contemplativas. Utilizando una terminología de raigambre «weberiana» distinguimos entre el tipo «intra-mundano» y el «extra-mundano» 0 «negador del mundo» (Weber 1984: 428-429). En el primer caso, se hace referencia a la propensión a encuadrarse en organizaciones que pretenden transformar la sociedad. En el segundo, se alude al distanciamiento intelectual propio del erudito o del esteta. El eje horizontal estructura el campo a partir de la división entre innovación y tradición. Conforme se va de izquierda a derecha, se pasa de las propiedades que indican el vínculo con la heterodoxia y la crítica, a las que señalan la conformidad con las rutinas académicas y el cultivo del canon.

A tenor de lo que nos dice el Gráfico I, obtendríamos cuatro combinaciones de propiedades. En primer lugar, la correspondiente al «intramundano-innovador» (primer cuadrante arriba izquierda). Este concentraría la apuesta por una «filosofía adjetiva», en este caso de carácter científico -contrapuesta a la «pureza» y sustantividad filosóficas del docto, el talante crítico y la vocación militante-. El capital cultural procede en este caso del cultivo de las ciencias formales y empíricas. Al mismo tiempo que gozan de una importante presencia en la base de datos ISI, han publicado alguna obra que ha sido traducida a otros idiomas. Tienen tendencia a formarse en Italia y en los países anglosajones; exhiben una producción mixta, combinándose lo escolar con lo ensayístico. Optan por editoriales no estrictamente académicas y acumulan cargos de diversa índole, tanto político-administrativos, como intelectuales y académicos.

La segunda combinación corresponde al «intramundano-tradicional» (segundo cuadrante, arriba derecha). El prototipo lo representaría el filósofo que, a la militancia (por ejemplo en organizaciones religiosas), une una trayectoria eminentemente profesoral. En este caso, se verifica el acceso tardío a la cátedra, la opción por editoriales de corte pedagógico y la escasa presencia en la base de datos ISI. En esta fracción son menos frecuentes los premios y, cuando estos se dan, reconocen los méritos académicos.

En tercer lugar, encontraríamos la combinación correspondiente al «innovador-extramundano» (tercer cuadrante, abajo izquierda). Este responde a la figura del esteta. Comparte con el anterior la reticencia a militar en organizaciones -lo que no impide su compromiso político desde la distancia del intelectual- pero su distanciamiento responde más al desapego contemplativo del artista (poco proclive a mancharse en el fango pragmático de la militancia) que a la torre de marfil propia del erudito (Collins 2005: 653). Como se puede constatar en el Gráfico I, el capital preferente en este cuadrante es de procedencia artística y literaria; prevalece la producción ensayística y dentro de editoriales que hemos definido como comerciales. Se inclinan por asumir cargos intelectuales, reciben premios a la creación de vanguardia, han tenido un acceso precoz a la cátedra universitaria y optan por formarse en países francófonos. Una peculiaridad de este 
Gráfico 1.

Gráfico de Correspondencias: el campo filosófico español (1963-1990).

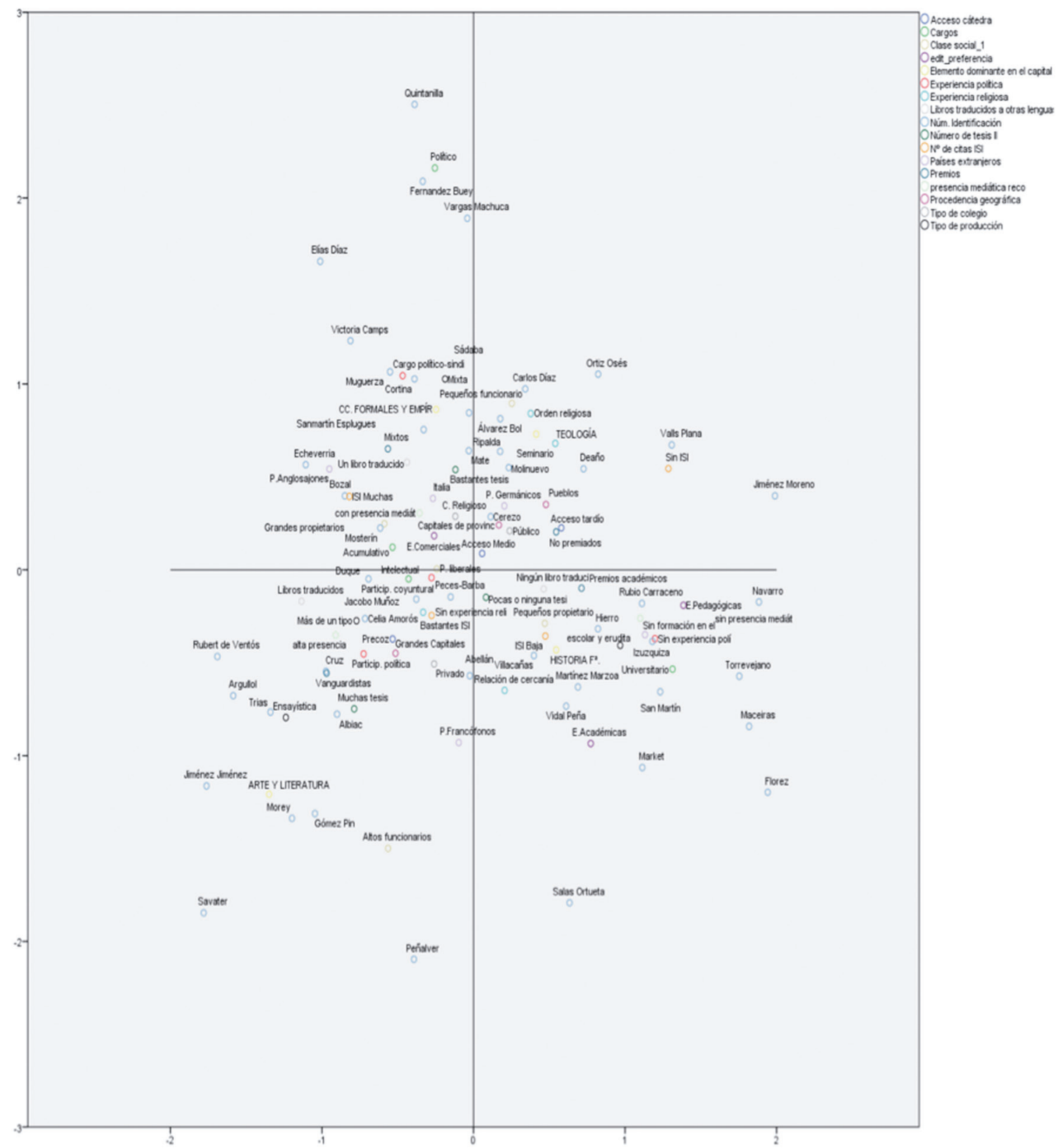

grupo es la abundante presencia de libros traducidos a otros idiomas.

Por último, se obtendría la combinación correspondiente al «tradicional-extramundano» (cuarto cuadrante, abajo derecha). Este responde a la figura del docto acumulando atributos como la posesión de un capital preferentemente histórico filosófico; la producción escolar y erudita, los premios de claro corte académico y cargos de índole exclusivamente universitaria. Publica preferentemente en editoriales académicas y pedagógicas, suele tener una baja presencia en la base de datos ISI y la formación en el extranjero es reducida o se limita al mundo germánico.

En el cuadrante número 1, correspondiente a los «innovadores-intramundanos», se constata que estos filósofos tienden a desarrollar una actividad política o sindical intensa. Aquí se ubican muchos de los militantes de izquierda que en el curso de la Transición hicieron carrera política (Abellán 2005: 266-295; Pecourt 2008). Asimismo, se trata de intelectuales con una apreciable proyección mediática (Negró Acedo 2006). En su mayor parte se formaron en colegios de tipo confesional, aunque hay que tener en cuenta que esta categoría es compartida por más de uno de cada dos filósofos de la muestra analizada. Esta formación no se traduce sin embargo en un fuerte compromiso con organizaciones religiosas sino a lo sumo en una participación coyuntural. Respecto su procedencia social, sus padres pertenecen principalmente a fracciones de las clases acomodadas: grandes propietarios y profesiones liberales (abogados, médicos, ingenieros). 
En el cuadrante número dos, ocupado por los «tradicionales-intramundanos», se concentran los filósofos con un ascendiente religioso más intenso: formación en seminarios e incluso pertenencia a órdenes religiosas. De origen mayoritariamente rural, han nacido en pueblos o en capitales de provincia. Son vástagos del pequeño funcionariado, la pequeña burguesía agrícola y, en escasa medida, de la clase obrera.

En el cuadrante tres, donde se emplazan los «innovadores-extramundanos», se alojan los intelectuales con mayor presencia en los medios. Nacidos en las grandes capitales, suelen estudiar en colegios privados, eventualmente no confesionales. Menos involucrados en la militancia religiosa, presentan una escasa implicación en la militancia política, que no obsta para que se pronuncien desde la distancia del intelectual puro, sobre los asuntos de la política cotidiana (v. g. firma de manifiestos, escritos de protesta...). Su clase social de origen se corresponde con las profesiones liberales y el alto funcionariado (notarios, catedráticos...).

En el cuarto cuadrante, ocupado por los «tradicionales extramundanos», se sitúan los filósofos que se ajustan fielmente al perfil del profesor. Carentes de presencia en los medios de comunicación y en la arena política, revelan escasas propensiones al activismo religioso. En su mayor parte son hijos de pequeños propietarios rurales.

En la Tabla II, agrupamos las propiedades internas y externas obtenidas en el análisis de correspondencias múltiples junto con los filósofos en cada tipo de categoría.

\section{ConCLUSIONES}

El espacio de puntos construido a partir del análisis de correspondencias múltiples y la tipología de perfiles filosóficos («innovador intramundano», «tradicional intramundano», «innovador extramundano» y «tradicional extramundano») derivada del mismo, se pueden poner en relación con las redes y nódulos diferenciados en la obra Herederos y Pretendientes. Obviamente, los individuos figurados por los puntos en el espacio, no representan a las subjetividades concretas, de carne y hueso, con sus avatares biográficos pertinentes. Se trata de «individuos construidos», abstracciones obtenidas por la combinación ideal típica de una serie de atributos seleccionados y susceptibles de cuantificación (Bourdieu 1984: 13-21). El nombre propio, requerido para la identificación, designa a este individuo construido, como si se tratara de una suerte de proyección estenográfica de propiedades diversas.

Pues bien, los filósofos pertenecientes a lo que en el mencionado libro se denominaba «red oficial», se ajustan bien al tipo del «tradicional extramundano» incluido en el cuarto cuadrante de nuestro análisis. Aglutinando en ella las propiedades del «pensador puro» y reacio a hibridar la filosofía con otros saberes ajenos, en esta zona se concentran los profesores de filosofía que integraron tanto el nódulo opusdeísta como el constituido por el eje RábadeMontero. Como se indicó, en el curso de la década de los setenta y desgajándose en cierto modo de esta red oficial, se configuraron dos nódulos que calificamos de «heterodoxia académica» y que corresponden a los grupos encabezados, respectivamente, por Gustavo Bueno y Manuel Garrido. Aunque en la muestra utilizada, los filósofos de este subsector aparecen muy poco representados, se les puede localizar, bien próximos al cuarto cuadrante, ocupado por los «tradicionales extramundanos» (es el caso de Vidal Peña, discípulo de Bueno), bien en situación de migrar hacia el primer cuadrante, que corresponde a los «innovadores intramundanos» (este es el caso de José Sanmartín, discípulo de Manuel Garrido), donde tienden a emplazarse los poseedores de un capital cultural de predominio científico y lógico-formal.

Por su parte, los filósofos vinculados a la denominada «red alternativa» y a sus nódulos de pertenencia, se distribuyen entre los cuadrantes primero, segundo y tercero. Esta división, que distingue a los «innovadores intramundanos», los «tradicionales intramundanos» y los «innovadores extramundanos», se correlaciona estrechamente con la estipulada, dentro del nódulo nucleado en torno a Aranguren, entre polo científico, polo religioso y polo artístico.

En el primer caso nos encontramos con pensadores que combinan la asunción de cargos de responsabilidad política con la posesión de un capital cuyo elemento predominante lo constituyen las ciencias empíricas (naturales o humanas) y la lógica. Javier Muguerza, Elías Díaz, Miguel Ángel Quintanilla, Victoria Camps o Celia Amorós, entre otros, se alojarían en este sector.

En segundo lugar, y dentro asimismo del nódulo de Aranguren, se destaca un elenco de filósofos que, contando con recursos intelectuales de índole predominantemente teológica e histórico-filosófica, articulan un discurso de acentos proféticos, con clara vocación emancipatoria (Díaz Salazar 2006: 160-162 y García Santesmases 2010). Se trata de lo que hemos denominado tradicionales intramundanos, entre los que destacan autores como Reyes Mate, Álvarez Bolado, Pedro Cerezo o Valls Plana.

En tercer lugar y dentro de este mismo nódulo tripolar, se sitúan los pensadores dotados con disposiciones y recursos más afines al arte y la literatura. Son también poco dados a asumir cargos de responsabilidad política, lo que no impide su continua toma de posición en los medios de comunicación, donde gozan de una importante acogida. Aquí se inscribe el grupo de filósofos «luditrágicos» 0 nietzscheanos, una bohemia vanguardista representada, entre otros, por Eugenio Trías, Fernando Savater, Víctor Gómez Pin o Miguel Morey (Vázquez García 2011; Santana 2012). Tienden a concentrarse en el tercer cuadrante, que corresponde a los «innovadores extramundanos». 
Tabla 2

Campo filosófico (tipología).

\begin{tabular}{|c|c|c|c|}
\hline Tipos filosóficos & Propiedades internas & Propiedades externas & Filósofos ${ }^{10}$ \\
\hline Intramundano-innovador & $\begin{array}{l}\text { Ciencias formales y empíricas } \\
\text { Producción mixta } \\
\text { Países anglosajones e Italia } \\
\text { Cargos políticos }\end{array}$ & $\begin{array}{c}\text { Cargo político/sindical } \\
\text { Alta proyección mediática } \\
\text { Participación coyuntural org. religiosa } \\
\text { Grandes propietarios/profesiones } \\
\text { liberales y pequeño funcionariado }\end{array}$ & $\begin{array}{c}\text { Quintanilla } \\
\text { Fernández Buey } \\
\text { Vargas-Machuca } \\
\text { Sádaba } \\
\text { Muguerza } \\
\text { Cortina } \\
\text { Sanmartín Esplugues } \\
\text { Echeverría } \\
\text { Bozal } \\
\text { Mosterín } \\
\text { Duque } \\
\text { Jacobo Muñoz } \\
\text { Celia Amorós } \\
\text { Peces Barba }\end{array}$ \\
\hline Intramundano-tradicional & $\begin{array}{l}\text { Teología y cultura religiosa } \\
\text { Producción escolar } \\
\text { Países germánicos } \\
\text { Escasa ocupación de cargos }\end{array}$ & $\begin{array}{c}\text { Experiencia política escasa } \\
\text { Sin presencia mediática } \\
\text { Pertenencia organización religiosa } \\
\text { Pequeña burguesía administrativa y } \\
\text { agrícola }\end{array}$ & $\begin{array}{c}\text { Ortíz Osés } \\
\text { Carlos Díaz } \\
\text { Álvarez Bolado } \\
\text { Ripalda } \\
\text { Valls } \\
\text { Reyes Mate } \\
\text { Molinuevo } \\
\text { Cerezo } \\
\text { Peces Barba } \\
\text { Rubio Carracedo } \\
\text { Deaño }{ }^{11} \\
\text { Jiménez Moreno }\end{array}$ \\
\hline Innovador-extramundano & $\begin{array}{c}\text { Arte y literatura } \\
\text { Producción ensayística } \\
\text { Francia } \\
\text { Cargos intelectuales }\end{array}$ & $\begin{array}{c}\text { Participación política } \\
\text { Alta proyección mediática } \\
\text { Poco contacto con org. religiosa } \\
\text { Profesiones liberales y alto } \\
\text { funcionariado }\end{array}$ & $\begin{array}{c}\text { Manuel Cruz } \\
\text { Peñalver } \\
\text { Albiac } \\
\text { Argullol } \\
\text { Trías } \\
\text { Jiménez Jiménez } \\
\text { Rubert de Ventós } \\
\text { Gómez Pin } \\
\text { Morey } \\
\text { Savater }\end{array}$ \\
\hline Tradicional-extramundano & $\begin{array}{c}\text { Historia de la filosofía } \\
\text { Producción escolar y erudita } \\
\text { No viajan/Países germánicos } \\
\text { Cargos universitarios }\end{array}$ & $\begin{array}{l}\text { Experiencia política escasa } \\
\text { Sin presencia mediática } \\
\text { Participación en org.religiosa } \\
\text { Pequeños propietarios }\end{array}$ & $\begin{array}{c}\text { Maceiras } \\
\text { Izuzquiza } \\
\text { Hierro } \\
\text { Flórez } \\
\text { Torrevejano } \\
\text { Villacañas } \\
\text { Martínez Marzoa } \\
\text { Navarro Cordón } \\
\text { Javier San Martín } \\
\text { Rubio Carracedo } \\
\text { Vidal Peña } \\
\text { Market } \\
\text { Abellán } \\
\text { Salas Ortueta }\end{array}$ \\
\hline
\end{tabular}

Fuente: Elaboración propia.

10 Aunque la distribución de los filósofos de la muestra en los cuadrantes del gráfico no coincide totalmente con la taxonomía de "nódulos" establecida en Vázquez García (2009) (por ejemplo, en los casos de Manuel Cruz o de Gabriel Albiac), el modelo estadístico mantiene la coherencia semántica global con el modelo cualitativo presentado en el libro. Los ejes trazados no definen fronteras rígidas sino que deben ayudar a delimitar regiones con un valor probabilístico interpretable.

11 La trayectoria de Alfredo Deaño (1944-1978), truncada por su temprana muerte, lo convierte en un caso estadísticamente atípico, de ahí que figure en un cuadrante que no corresponde en absoluto con el derivado del análisis cualitativo. 
Finalmente, y dentro de la red alternativa, se diferenciaba en Herederos y Pretendientes un nódulo nucleado en Barcelona en torno a la figura de Manuel Sacristán. Estos filósofos, dotados a la vez de importantes competencias científicas y de una intensa experiencia política, se ubicarían, como sucede con una de las constelaciones de la órbita Aranguren, en el cuadrante de los «innovadores intramundanos». Filósofos como Jacobo Muñoz, Valeriano Bozal o Francisco Fernández Buey estarían próximos a este sector.

De este modo, recurriendo al análisis de correspondencias múltiples, se proporcionan elementos probatorios de carácter cuantitativo, a favor del modelo propuesto en Herederos y Pretendientes. La confirmación mediante el procedimiento cuantitativo constituía un desafío e implicaba riesgos, pues suponía dificultar el trabajo de «ejemplificación» (Passeron 2006: 599-602) previamente realizado. Pero los resultados muestran la cohesión semántica de la cuantificación efectuada respecto a la interpretación cualitativa realizada con anterioridad. De este modo, la potencia demostrativa de la red de descripción que se formuló, sale reforzada. Las agrupaciones y taxonomías comparativas estipuladas en el mencionado libro mediante el recurso al análisis documental, se verían ahora corroboradas recurriendo a una técnica estadística. Quedaría así en evidencia, por consiguiente, el «pluralismo metodológico» (Roth 1989; Bericat 1998) de una disciplina tan novedosa como la sociología de la filosofía. Se demuestra así la posibilidad de integrar recíprocamente, los procedimientos cualitativos y los cuantitativos, en una "ciencia histórica» donde, hasta la fecha y salvo excepciones, solo los métodos del primer tipo estaban a la orden del día.

\section{RefERENCIAS BiBLIOGRÁfICAS}

Abellán, José Luis. 2005. Ortega y Gasset y los orígenes de la Transición democrática. Madrid: Espasa.

Afinoguénova, Eugenia. 2003. El idiota superviviente. Artes y letras españolas frente a la 'muerte del hombre', 1969-1980. Madrid: Libertarias.

Barrera, Carlos. 1995. Sin mordaza, veinte años de prensa en democracia. Madrid: Temas de Hoy.

Barrios, Manuel. 2010. «La filosofía española». El Cultural, 19-25 de febrero.

Bericat, Eduardo. 1998. La integración de los métodos cuantitativo y cualitativo en la investigación social. Significado y medida. Barcelona: Ariel.

Bolado, Gerardo. 2001. Transición y recepción: la filosofía española en el último tercio del siglo XX. Santander: Sociedad Menéndez Pelayo

Bourdieu, Pierre. 1984. Homo Academicus. Paris: Les Éditions de Minuit.

Bourdieu, Pierre. 1988. La distinción. Madrid: Taurus.

Bourdieu, Pierre. 1996. Sur la télévision. Paris: Liber.

Bourdieu, Pierre. 2000. Propos sur le champ politique. Lyon: Presses Universitaires de Lyon.

Caballero Bono, José Luis. 2008. Ocho filósofos españoles contemporáneos. Madrid: Diálogo Filosófico.
Campillo, Antonio. 2011. «La transición filosófica en España». Daimon. Revista Internacional de Filosofía 53:147-156.

Díaz Salazar, Rafael. 2006. El factor católico en la política española. Del nacionalcatolicismo al laicismo. Madrid: PPC.

Estrella González, Alejandro. 2012. Clío ante el espejo. Un socioanálisis de E. P. Thompson. Cádiz-México: Servicio de Publicaciones de la Universidad de Cádiz, Universidad Autónoma Metropolitana Cuajimalpa.

Flórez Miguel, Cirilo. 1978. «Panorama de la vida filosófica en España, hoy». Pp. 329-348 en Actas del II Seminario de Historia de la Filosofía española, tomo I, editado por Antonio Heredia Soriano. Salamanca: Ed. Universidad de Salamanca.

Fuentes Aragonés, Juan Francisco. 2006. «Lo que los españoles Ilaman la Transición. Evolución histórica de un concepto clave». Mélanges de la Casa de Vélazquez 36:131-149.

Galván García, Valentín. 2010. De vagos y maleantes. Michel Foucault en España. Barcelona: Virus Editorial.

García Santesmases, Antonio. 2010. «Intelectuales y cuestión religiosa en la España actual. Pistas para un análisis socio-político». Iglesia Viva 243:85-96.

Garrido, Manuel, Nelson Orringer, Luis Manuel Valdés y Margarita María Valdés. 2009. El legado filosófico español e hispanoamericano del siglo XX. Madrid: Cátedra.

Gil Villegas, Fernando. 1996. Los profetas y el Mesías. Lukács y Ortega como precursores de Heidegger en el 'Zeitgeist' de la Modernidad (1900-1929). México: FCE.

Gracia, Jordi. 2010. «Filósofos en el espacio público». Babelia, 3 de julio. Gracia, Jordi y Domingo Ródenas. 2009. El ensayo español. Siglo XX. Barcelona: Crítica.

Greenacre, Michael. 2008. La práctica del análisis de correspondencias. Madrid: Fundación BBVA.

Jiménez, Antonio y Manuel Maceiras. 2002. "Panorama actual del pensamiento filosófico español”. Pp. 307-335 en Pensamiento filosófico español, Vol. II, Del Barroco a nuestros días, editado por Manuel Maceiras Fafián. Madrid: Síntesis.

Le Roux, Brigitte y Henry Rouanet. 2004. Geometric Data Analysis. Dordrecht: Kluwer Academic Publishers.

(Van) Leeuwen, Marco, Ineke Maas y Andrew Miles. 2002. Historical international classification of occupations (hisco). Leeuwen: Leeuwen University Press.

Mannheim, Karl. 1993. «El problema de las generaciones». Revista española de Investigaciones Sociológicas 62:193-242. http:/l dx.doi.org/10.2307/40183643

Marqués Perales, Ildefonso. 2008. Génesis de la teoría social de Pierre Bourdieu. Madrid: CIS.

Mauger, Gérard. 2009. "Générations et rapports de generations». Daimon. Revista de Filosofía 46:109-126.

Moreno Pestaña, José Luis. 2005. «La sociología de la filosofía de Pierre Bourdieu y del Centre de Sociologie Européenne». Revista Española de Investigaciones Sociológicas 112:1342. http://dx.doi.org/10.2307/40184711

Moreno Pestaña, José Luis. 2006. En devenant Foucault. Sociogénèse d'un grand philosophe. Paris: Éditions du Croquant.

Moreno Pestaña, José Luis. 2007. «Randall Collins y la dimensión ritual de la filosofía». Revista Española de Sociología 8:115-137.

Moreno Pestaña, José Luis. 2008. Filosofía y sociología en Jesús Ibáñez. Genealogía de un pensador crítico. Madrid: Siglo XXI.

Moreno Pesta-a, José Luis. 2012a. «Un programa para la sociología de la filosofía». Revista Internacional de Sociología 70:263-284. http://dx.doi.org/10.3989/ris.2010.07.05

Moreno Pestaña, José Luis. 2012b. La norma de la filosofía. La configuración del patrón filosófico español tras la guerra civil. Madrid: Biblioteca Nueva.

Moreno Pestaña, José Luis. 2012c. «Sobre "Herederos y Pretendentes". Un diálogo con Francisco Vázquez». Isegoría. Revista de Filosofía Moral y Politica 46:295-302. 
Moreno Pestaña, José Luis y Francisco Vázquez García. 2006. Pierre Bourdieu y la filosofía. Barcelona: Montesinos.

Muguerza, Javier. 2010. «Una mirada atrás y otra adelante» (respuesta a Francisco Vázquez). Daimon. Revista Internacional de Filosofía 50:105-114.

Negró Acedo, Luis. 2006. El diario 'El País' y la cultura de las élites durante la Transición. Madrid: Foca.

Passeron, Jean Claude. 2006. Le raisonnement sociologique. Un espace non poppérien de l'argumentation. Paris: Albin Michel.

Pecourt, Juan. 2008. Los intelectuales y la transición política. Un estudio del campo de las revistas políticas en España. Madrid: CIS.

Plata Parga, Gabriel. 2010. De la revolución a la sociedad de consumo. Ocho intelectuales en el tardofranquismo y la democracia. Madrid: UNED.

Ribas, Pedro. 2006. «Años de penitencia: la filosofía en España durante el franquismo». Pp. 31-47 en Pensar en tiempos de oscuridad. Homenaje al profesor Sergio Vences, editado por Juan Carlos Couceiro-Bueno. A Coruña: Universidade da Coruña, Servizio de Publicacions.

Ribas, Pedro. 2011. «Filosofía, religión y política en la España contemporánea». Iberoamericana. América Latina-EspañaPortugal. Ensayos sobre letras, historia y sociedad. Notas. Reseñas iberoamericanas 42:189-208.

Roth, Paul Andrew. 1989. Meaning and method in the social sciences. A case for methodological pluralism. Ithaca: Cornell University Press

Ruiz de Samaniego, Alberto y Miguel Ángel Ramos. 2002. La generación de la democracia. Nuevo pensamiento filosófico en España. Madrid: Tecnos.

Santana, Sandra. 2012. «Die Fröliche Wissenschaft der Kulturindustrie. Zur Aufnahme Nietzsches im Spanischen Kulturrer und der Siebziger Jahre». Pp. 9-24 en Nietzsche und die Postmoderne, editado por André Reichert, Jaime de Salas y Ulrich Johannes Schneider. Leipzig: Leipziger Universitäts Verlag.

Sauquillo, Julián. 2011. «Herederos y conquistadores. La transición filosófica española». Claves de Razón Práctica 211:50-57.

Savignano, Armando. 2008. Panorama de la filosofía española del siglo XX. Granada: Comares.
Serra, Xavier. 2010. Historia social de la filosofía catalana. La Lógica (1900-1980). Barcelona: Editorial Afers.

Suances Marcos, Manuel. 2006. Historia de la filosofía española contemporánea. Madrid: Síntesis.

Vázquez García, Francisco. 2009. La filosofía española. Herederos y pretendientes. Una lectura sociológica (1963-1990). Madrid: Abada.

Vázquez García, Francisco. 2011. «Rituales de interacción y especies de capital en el neonietzscheanismo español». Daimon. Revista de Filosofía 53:47-66.

Villacañas, José Luis. 2010. «Una mirada supeditada al método». Revista de Libros 168:27-28.

Weber, Max. 1984. Economía y sociedad. Esbozo de sociología comprensiva. Madrid: FCE.

FRANCISCO VÁZQUEZ GARCÍA es Catedrático de filosofía por la Universidad de Cádiz. Miembro del grupo de investigación "El problema de la alteridad en el mundo actual" (HUM-536). Sus últimas dos publicaciones relevantes en el ámbito de la sociología de la filosofía son: "Rituales de interacción y especies de capital en el neonietzscheanismo español (1968-1976)", Daimon. Revista Internacional de Filosofía, 53 (2011), pp. 47-66 y "La primera recepción española de la epistemología histórica francesa: Gaston Bachelard (1940-1959)", Theoria. Revista de Teoría, Historia y Fundamentos de la Ciencia , 28 (2013) (2), n 77, pp. 303-326.

ILDEFONSO MARQUÉS PERALES es Profesor Contratado Doctor por la Universidad de Sevilla. Esta investigación está financiada por el Ministerio de Educación, Cultura y Deporte del Gobierno de España (CSO02011-29346). Sus últimas publicaciones son "Belief about social mobility and Social Policy Preferences", Journal of European Social Policy (en prensa); "Razón sin deliberación: filosofía, sociología y neurociencia", en Revista Latina de Sociología, 2 (2012), pp.42-45 y "Somos más móviles. Nuevas evidencias sobre la movilidad social intergeneracional de clase en la segunda mitad del S.XX", Revista Española de Investigaciones Sociológicas, 131, (2010), pp.43-73. 
ANEXO

Tabla 1.

Estadísticas descriptivas (ubicadas en un anexo indicado al final).

\begin{tabular}{|c|c|c|c|c|}
\hline Variables & Media & Desv. Típica & Mínimo & Máximo \\
\hline \multicolumn{5}{|l|}{ Variables internas } \\
\hline Acceso a Cátedra & 1,90 & 0,68 & 1 & 3 \\
\hline Cargos & 2,27 & 1,07 & 1 & 4 \\
\hline Editorial de preferencia & 2,57 & 0,76 & 1 & 3 \\
\hline Elemento dominante del capital cultural & 2,08 & 1,10 & 1 & 4 \\
\hline Libros traducidos a otras lenguas & 2,44 & 0,81 & 1 & 3 \\
\hline Número de tesis dirigidas & 2,74 & 0,63 & 1 & 3 \\
\hline Número de citas ISI & 2,28 & 1,01 & 1 & 4 \\
\hline Países extranjeros & 2,20 & 1,33 & 1 & 5 \\
\hline Premios & 2,84 & 1,14 & 1 & 4 \\
\hline Tipo de producción & 2,10 & 0,93 & 1 & 4 \\
\hline \multicolumn{5}{|l|}{ Variables externas } \\
\hline Clase social & 3,30 & 1,41 & 1 & 5 \\
\hline Tipo de colegio & 2,17 & 0,63 & 1 & 3 \\
\hline Experiencia política & 2,66 & 1,09 & 1 & 4 \\
\hline Pertenencia a org. religiosas & 3,14 & 1,06 & 1 & 4 \\
\hline Presencia mediática & 2,12 & 0,71 & 1 & 3 \\
\hline Procedencia geográfica & 1,96 & 0,90 & 1 & 3 \\
\hline
\end{tabular}

